University of Nebraska - Lincoln

DigitalCommons@University of Nebraska - Lincoln

$9-19-2008$

\title{
Political Attitudes Vary with Physiological Traits
}

\author{
Douglas R. Oxley \\ University of Nebraska - Lincoln \\ Kevin Smith \\ University of Nebraska-Lincoln, ksmith1@unl.edu \\ John R. Alford \\ Rice University, jra@rice.edu \\ Matthew V. Hibbing \\ University of Illinois, Urbana-Champaign, mhibbing@ucmerced.edu \\ Jennifer L. Miller \\ University of Nebraska - Lincoln, jmiller12@unl.edu
}

See next page for additional authors

Follow this and additional works at: https://digitalcommons.unl.edu/poliscifacpub

Part of the Political Science Commons

Oxley, Douglas R.; Smith, Kevin; Alford, John R.; Hibbing, Matthew V.; Miller, Jennifer L.; Scalora, Mario J.; Hatemi, Peter K.; and Hibbing, John R., "Political Attitudes Vary with Physiological Traits" (2008). Faculty Publications: Political Science. 26.

https://digitalcommons.unl.edu/poliscifacpub/26

This Article is brought to you for free and open access by the Political Science, Department of at DigitalCommons@University of Nebraska - Lincoln. It has been accepted for inclusion in Faculty Publications: Political Science by an authorized administrator of DigitalCommons@University of Nebraska - Lincoln. 


\section{Authors}

Douglas R. Oxley, Kevin Smith, John R. Alford, Matthew V. Hibbing, Jennifer L. Miller, Mario J. Scalora, Peter K. Hatemi, and John R. Hibbing 


\title{
Political Attitudes Vary with Physiological Traits
}

\author{
Douglas R. Oxley,' Kevin B. Smith,' John R. Alford, ${ }^{2}$ Matthew V. Hibbing, ${ }^{3}$ Jennifer L. Miller,' Mario Scalora, ${ }^{4}$ \\ Peter K. Hatemi, ${ }^{5}$ John R. Hibbing'
}

\begin{abstract}
Although political views have been thought to arise largely from individuals' experiences, recent research suggests that they may have a biological basis. We present evidence that variations in political attitudes correlate with physiological traits. In a group of 46 adult participants with strong political beliefs, individuals with measurably lower physical sensitivities to sudden noises and threatening visual images were more likely to support foreign aid, liberal immigration policies, pacifism, and gun control, whereas individuals displaying measurably higher physiological reactions to those same stimuli were more likely to favor defense spending, capital punishment, patriotism, and the Iraq War. Thus, the degree to which individuals are physiologically responsive to threat appears to indicate the degree to which they advocate policies that protect the existing social structure from both external (outgroup) and internal (norm-violator) threats.
\end{abstract}

I Department of Political Science, University of Nebraska-Lincoln, Lincoln, NE 68588, USA.

2 Department of Political Science, Rice University, Houston, TX 7725I, USA.

3 Department of Political Science, University of Illinois, Urbana-Champaign, Urbana, IL 6I80I, USA.

4 Department of Psychology, University of Nebraska-Lincoln, Lincoln, NE 68588, USA.

5 Virginia Institute for Psychiatric and Behavioral Genetics, Richmond,VA 23298, USA.

Corresponding author:J. R. Hibbing, email jhibbing@unl.edu

$\mathrm{T}$ he nature and source of political attitudes have been the subject of much study (1-3). Traditionally, such attitudes were believed to be built from sensible, unencumbered reactions to environmental events (4), but more recent research emphasizes the built-in, almost "automated" quality of many political responses (5), which has been suggested to be based in brain activation variations in limbic regions (6-8). The research task is now to determine why some people seem primed to adopt certain political attitudes, whereas others appear primed to adopt quite different attitudes. For example, although images and reminders of the terrorist attacks of September 11, 2001, produce an aggregate shift in political views $(9,10)$, the reasons for individual variability in the degree of attitudinal shifts are unknown.

One possibility is that people vary in general physiology and that certain of these variations encourage the adoption of particular political attitudes. Broad, physiologically relevant traits such as feelings of disgust and fear of disease have been suggested to be related to political attitudes (11, 12), and political beliefs can be predicted by observing brain activation patterns in response to unanticipated events, such as one letter of the alphabet appearing on a computer screen when the respondent expected a different letter (13). A connection between self-reports of felt threat and political attitudes has also been identified in previous research (14-19).

The physiology of response to a perceived threat is an attractive topic of investigation because an appropriate response to environmental threat is necessary for longterm survival and because perceived threat produces a variety of reasonably well- mapped, physically instantiated responses (20). If the threat is abrupt, a defensive cascade of linked, rapid extensor-flexor movement occurs throughout the body within 30 to $50 \mathrm{~ms}$ (21), presumably to reduce vital-organ vulnerability (e.g., eye blink and retraction of the head). Less immediately, perceived threat causes signals from the sensory cortex to be relayed to the thalamus and ultimately to the brain stem, resulting in heightened noradrenergic activity in the locus ceruleus (22). Acetylcholine, acting primarily through the amygdala but also through the hypothalamic-pituitary-adrenal axis (23), stimulates release of epinephrine, which in turn leads to activation of the sympathetic division of the autonomic nervous system. Though these basic response patterns apply in all people, individual sensitivity to perceived threat varies widely (24).

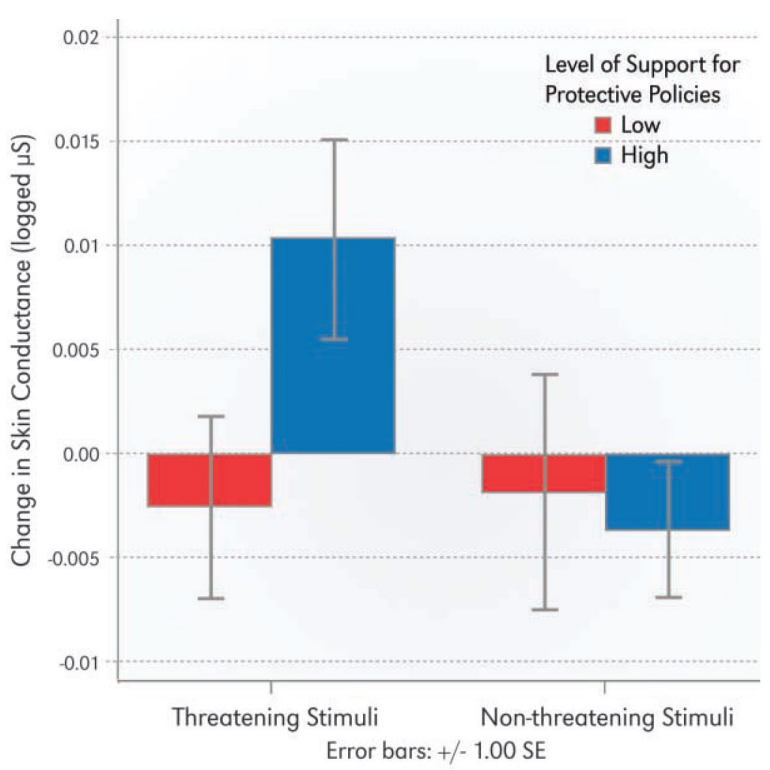

Figure I. Changes in skin conductance (in microsiemens) resulting from the viewing of threatening and nonthreatening images for high supporters and low supporters of socially protective policies. Difference of means tests: threatening stimuli $t=1.98, P=0.05$; nonthreatening stimuli $t=0.284, P$ $=0.77$, two-tailed tests. All skin conductance data have been logged. Support for policies is measured by self-reported positions on 18 issues relevant to group life (see text), with "high support" including those participants above the median of support and "low support" including those participants below the median. 
Skin conductance "has been closely linked with the psychological concepts of emotion, arousal, and attention" and "provides relatively direct and undiluted representation of sympathetic activity" (26). Arousal causes increased moisture in the outer layers of the skin that in turn enhances conductivity, making it possible to assess sympathetic activation by recording changes in the level of skin conductance. Each participant was shown three separate threatening images (a very large spider on the face of a frightened person, a dazed individual with a bloody face, and an open wound with maggots in it) interspersed among a sequence of 33 images. After logging the data to normalize the distribution, we computed the change in the mean level of skin conductance (SCL) from the previous interstimulus interval $(10 \mathrm{~s})$ to the stimulus of interest $(20 \mathrm{~s})$. This calculation isolates the change in skin conductance induced by the stimulus and reduces the effects of baseline variations across participants (27). We computed the mean change in SCL induced by the three threatening stimuli and determined whether this mean difference was related to variations in preference for socially protective policies (described below). Similar procedures were conducted for three nonthreatening stimuli shown during the series (a bunny, a bowl of fruit, and a happy child).

The other physiological measure was orbicularis oculi startle blink response, an involuntary response to a startling noise. Harder blinks (higher blink amplitudes) are indicative of a heightened "fear state" (28). The threatening stimulus was a loud, standardized level of white noise heard by participants (through headphones) at seven unexpected moments while they were looking at a computer screen containing nothing but a focus point. As is common practice (28), we first took the logarithm of the data and then computed participants' average blink amplitude. Because surprising subjects with a sudden, jarring noise is likely to affect all physiological indicators, we conducted the startle portion of the study after completing separate tests on skin conductance. The order of the images and the timing of the auditory startle were randomized once, and then that program was presented to all participants.

The survey instrument contained a battery of items asking respondents whether they agreed with, disagreed with, or were uncertain toward 28 individual political concepts - the well-known Wilson-Patterson format (29). We identified particular positions on 18 of these policy issues as those most likely to be held by individuals particularly concerned with protecting the interests of the participants' group, defined as the United States in mid-2007, from threats. These positions are support for military spending, warrantless searches, the death penalty, the Patriot Act, obedience, patriotism, the Iraq War, school prayer, and Biblical truth; and opposition to pacifism, immigration, gun control, foreign aid, compromise, premarital sex, gay marriage, abortion rights, and pornography. We do not label these collections of policy positions as either "liberal" or "conservative" because we measure only one aspect of ideologies and exclude other aspects such as positions on economic issues. We take no stance on whether these positions actually promote the stability and cohesion of the social unit; we only assert that, given the common frames of the modern American policy, those most concerned about social protection will tend to be attracted to the particular policy positions listed.
We computed a summary measure of each participant's stances on the 18 political issues such that those positions suggesting a concern for protecting the social unit were given higher scores. To test the skin conductance portion of our analysis, we divided participants into two groups according to their level of concern for protecting the social unit: those above the median and those below. Participants whose policy positions suggest more concern for protecting the social unit were distinguished by an increase in skin conductance when threatening stimuli were presented (Figure 1). Those whose positions suggest less concern for protecting the social unit, by contrast, were mostly unaffected by those same stimuli and the difference in these two groups was statistically significant $(P=0.05)$. When participants were shown nonthreatening stimuli, there was no statistically significant difference $(P=0.77)$ in skin conductance changes between the two groups (Figure 1).

Uncontrolled, bivariate results have the potential to mislead. We therefore regressed each participant's summary level of support for socially protective political policies on changes in skin conductance as well as on four sociodemographic variables commonly used as predictors of political attitudes: gender, age, income, and education (race and ethnicity were not controlled because all but one participant was self-identified as white and non-Hispanic). With the effects of these sociodemographic variables controlled, the effect of increases in skin conductance when viewing threatening stimuli was positive and significant $(P<0.01)$, with a large standardized regression coefficient (0.377) (Table 1). When nonthreatening images were viewed, however, changes in skin conductance appeared to be unrelated to political attitudes pertaining to protecting the social

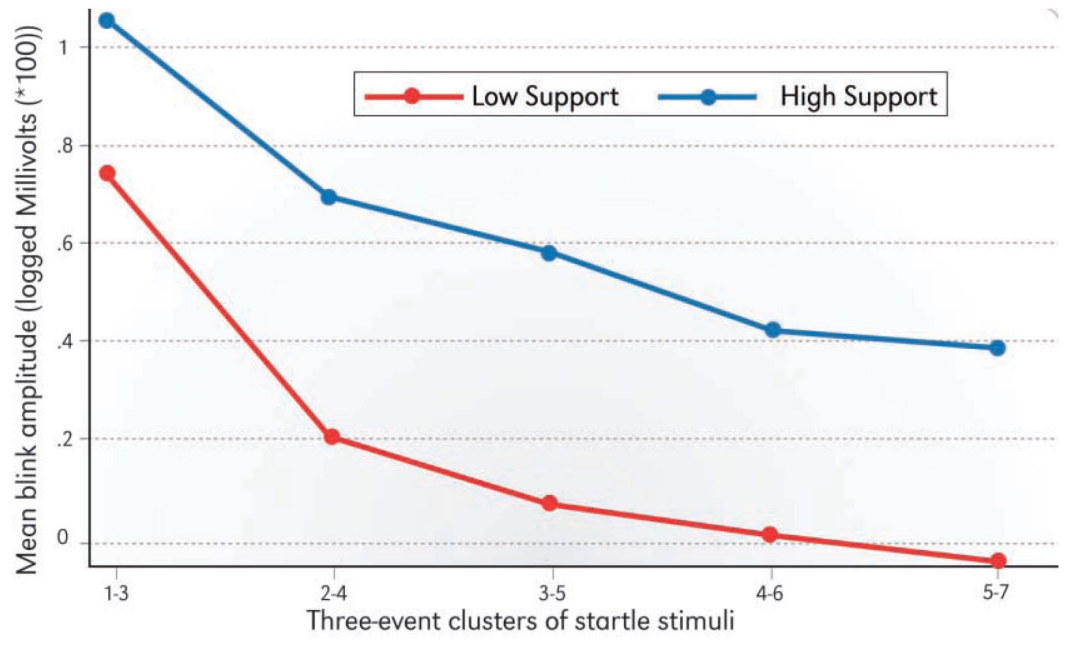

Figure 2. Three-event moving average of blink amplitude (in millivolts) in response to seven startling noises administered at unexpected times during the absence of visual stimuli for high supporters and low supporters of socially protective politics. Lines represent mean response for the two groups for each cluster of three responses and are designed to show habituation. All blink amplitude data have been converted to logarithm values so readings less than 0 are possible. Support for policies is as described in Figure I.

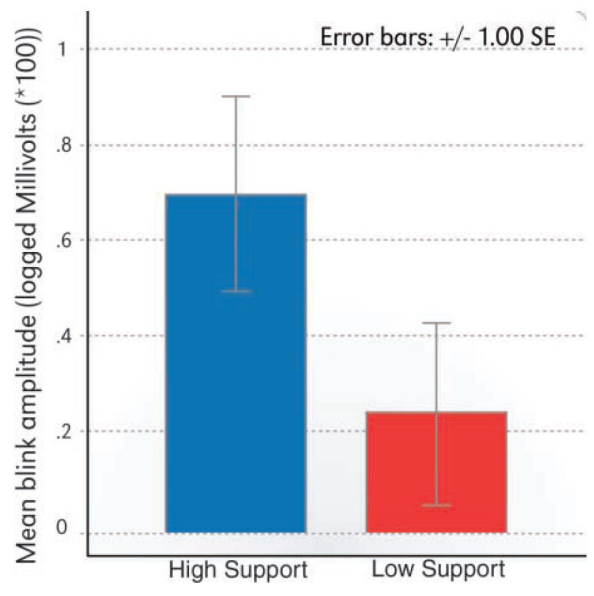

Figure 3. Mean blink amplitude in response to all seven startling noises for high supporters and low supporters of socially protective politics. Bars are mean blink amplitudes (in millivolts). Difference of means tests for overall means: $t=1.64, P=0.10$. Support for policies is as described in Figure I. 
order. In this multiple regression model, the standardized regression coefficient for skin conductance change was statistically insignificant $(P=0.96)$, small, and slightly negative $(-0.007)$ (Table 2$)$.

A further test of this pattern is possible when, for each participant, mean skin conductance change occasioned by the viewing

of the nonthreatening stimuli is subtracted from mean skin conductance change when viewing the threatening stimuli. When this variable was entered into the multiple regression with age, income, education, and gender, it was in the expected direction (greater relative reaction to threatening stimuli correlates with more support

Table I. Explaining support for socially protective policies with physiological reactions to threatening images. Results of ordinary least squares (OLS) regression with support for socially protective policies (possible range from 0 to 18), with higher numbers indicating attitudes more supportive of policies thought to protect the social unit regressed on five explanatory variables: gender $(0=$ male; I = female), age (in years), education (six categories ranging from "did not finish high school" to "college degree plus"), income (six categories ranging from an annual salary of less than $\$ 20,000$ to an annual salary of more than $\$ 100,000$ ), and changes in skin conductance level (SCL) occasioned by the viewing of threatening images. Descriptive statistics on the variables and further discussion of the regression techniques are available in the SOM. $* P<0.05$, two-tailed $t$ test.

\begin{tabular}{lrr}
\hline Variable & $\begin{array}{r}\text { Unstandardized } \\
\text { coefficient (SE) }\end{array}$ & $\begin{array}{r}\text { Standardized } \\
\text { coefficient }\end{array}$ \\
\hline SCL & $92.2^{*}(29.03)$ & 0.377 \\
Income & $-0.395(0.471)$ & -0.10 \\
Education & $-1.63^{*}(0.465)$ & -0.42 \\
Age & $0.19(0.10)$ & 0.235 \\
Gender & $-2.34(1.3)$ & -0.20 \\
Constant & $-353^{*}(193)$ & \\
$N$ & 46 & \\
Adj. R-square & 0.37 & \\
\hline
\end{tabular}

Table 2. Explaining support for socially protective policies with physiological reactions to nonthreatening images. Results of regression (OLS) with support for socially protective policies regressed on five explanatory variables. Variables are the same as those described for Table I except that skin conductance (SCL) is the change in skin conductance occasioned by the viewing of nonthreatening images. Descriptive statistics and further discussion of the regression techniques are available in the SOM. $* P<0.05$, two-tailed $t$ test.

\begin{tabular}{lrr}
\hline Variable & $\begin{array}{r}\text { Unstandardized } \\
\text { coefficient (SE) }\end{array}$ & $\begin{array}{r}\text { Standardized } \\
\text { coefficient }\end{array}$ \\
\hline SCL & $-1.8(35.08)$ & -0.007 \\
Income & $-0.438(0.533)$ & -0.115 \\
Education & $-1.57^{*}(0.53)$ & -0.408 \\
Age & $0.165(0.11)$ & 0.204 \\
Gender & $-2.23(1.52)$ & -0.196 \\
Constant & $-304^{*}(217)$ & \\
$N$ & 46 & \\
Adj. R-square & 0.21 & \\
\hline
\end{tabular}

Table 3. Explaining support for socially protective policies with blink amplitude in response to startling noises. Results of regression (OLS) with support for socially protective policies regressed on five explanatory variables. Variables are the same as those described for Table I except that mean amplitude is the mean blink amplitude for each participant following seven startle events (see Figure I). Descriptive statistics and further discussion of the regression techniques are available in the SOM, as is further discussion of the startle technique and measurement procedures. $* P<0.05$, twotailed $t$ test.

\begin{tabular}{lrr}
\hline Variable & $\begin{array}{r}\text { Unstandardized } \\
\text { coefficient (SE) }\end{array}$ & $\begin{array}{r}\text { Standardized } \\
\text { coefficient }\end{array}$ \\
\hline Mean amplitude & $1.67^{*}(0.75)$ & 0.286 \\
Income & $-0.320(0.500)$ & -0.08 \\
Education & $-1.76^{*}(0.498)$ & -0.458 \\
Age & $-0.187(0.10)$ & 0.232 \\
Gender & $-2.71(1.45)$ & -0.239 \\
Constant & $-348(204)$ & \\
$N$ & 46 & \\
Adj. R-square & 0.30 & \\
\hline
\end{tabular}

for socially protective policies), sizable (standardized regression coefficient $=0.28$, and statistically significant $(P=0.04)$. Full results of this analysis are presented in the supporting materials (following the References).

Startle blink EMG responses habituate (28) (Figure 2), but the tendency for high blink amplitudes to correlate with respondents supportive of protective policies was consistent across the exercise and was also apparent for the overall means (Figure 3). Although the difference was not significant in the bivariate analysis, when the sociodemographic controls were added to better specify the model, the coefficient for blink amplitude was again in the predicted (positive) direction, sizable (standardized regression coefficient $=0.286$ ), and statistically significant $(P=0.03)$ (Table 3 ).

Our data reveal a correlation between physiological responses to threat and political attitudes but do not permit firm conclusions concerning the specific causal processes at work. Particular physiological responses to threat could cause the adoption of certain political attitudes, or the holding of particular political attitudes could cause people to respond in a certain physiological way to environmental threats, but neither of these seems probable. More likely is that physiological responses to generic threats and political attitudes on policies related to protecting the social order may both derive from a common source. Parents could both socialize their children to hold certain political attitudes and condition them to respond in a certain way to threatening stimuli, but conditioning involuntary reflex responses takes immediate and sustained reinforcement and punishment, and it is unlikely that this conditioning varies systematically across political beliefs.

Alternatively, political attitudes and varying physiological responses to threat may both derive from neural activity patterns, perhaps those surrounding the amygdala. There is a connection between localized activation of the amygdala and aversive startle response (30). Amygdala activity is also crucial in shaping responses to socially threatening images $(31,32)$ and may be connected to political predispositions. Indeed, given that political and social attitudes are heritable (33-36) and that amygdala activity also has been traced to genetics (37-40), genetic variation relevant to amygdala activity could affect both physiological responses to threat and political attitudes bearing on threats to the social order.

Our findings suggest that political attitudes vary with physiological traits linked to divergent manners of experiencing and processing environmental threats. Consequently, our research provides one possible 
explanation for both the lack of malleability in the beliefs of individuals with strong political convictions and for the associated ubiquity of political conflict.

\section{References and Notes}

I. A. Campbell, P. E. Converse, W. E. Miller, D. E. Stokes, The American Voter (John Wiley, New York, 1960).

2. P. E. Converse, in Ideology and Discontent, D.E. Apter, Ed. (Free Press, New York, 1964).

3. J. R. Zaller, The Nature and Origins of Mass Opinion (Cambridge Univ. Press, New York, 1992).

4. B. I. Page, R.Y. Shapiro, The Rational Public (Univ. of Chicago Press, Chicago, 1992).

5. M. Lodge, C. Taber, Pol. Psychol. 26, 455 (2005).

6. G. E. Marcus,W. R. Neuman, M. Mackuen, Affective Intelligence and Political Judgment (Univ. of Chicago Press, Chicago, 2000).

7. R. McDermott, Perspect. Polit. 2, 69I (2004).

8. D. Westen, The Political Brain (Public Affairs, New York, 2007).

9. M. J. Landau et al., Pers. Soc. Psychol. Bull. 30, II 36 (2004).[Abstract]

10. S. Fahmy, S. Cho, W. Wanta, Y. Song, Vis. Commun. Q. I3, 3 (2006).

I I. J. Faulkner, M. Schaller, J. H. Park, L. A. Duncan, Group Process. Intergroup Relat. 7, 333 (2004).

I2. C. D. Navarrete, D. M. T. Fessler, Evol. Hum. Behav. 27, 270 (2006).

13. D. M.Amodio, J.T. Jost, S. L. Master, C. M. Lee,
Nat. Neurosci. I0, I 246 (2007)

14. J. T. Jost, J. Glaser, A. W. Kruglanski, F. J. Sulloway, Psychol. Bull. I29, 339 (2003).

I5. J.T. Jost, Am. Psychol. 6I, 65। (2006).

16. L. Huddy, S. Feldman, C. Taber, G. Lahav, Am. J. Pol. Sci. 49, 593 (2005).

17. S. Feldman, Pol. Psychol. 24, 593 (2003).

18. K. Stenner, The Authoritarian Dynamic (Cambridge Univ. Press, New York, 2005).

19. F. Pratto, J. Sidanius, L. M. Stallworth, B. F. Malle, J. Pers. Soc. Psychol. 67, 74I (1994).

20.W. B. Cannon, Bodily Changes in Pain, Hunger, Fear, and Rage (Appleton, New York, 1915).

2I. M. M. Bradley, P. J. Lang, in Handbook of Psychophysiology, J. T. Cacioppo, L. G. Tassinary, G. G. Berntson, Eds. (Cambridge Univ. Press, New York, 2007).

22. M. E. Thase, R. H. Howland, in Handbook of Depression, E. E. Beckham and W. R. Leber, Eds. (Guilford, New York, 1995).

23. E. Lemche et al., Hum. Brain Mapp. 27, 623 (2006).

24. G. H. Grosser, H. Wechser, M. Greenblatt, The Threat of Impending Disaster (MIT Press, Cambridge, MA, I97I).

25. Materials and methods are described in the SOM.

26. M. E. Dawson, A. M. Shell, D. L. Filion, in Handbook of Psychophysiology, J.T. Cacioppo, L. G. Tassinary, G. G. Berntson, Eds. (Cambridge Univ. Press, New York, 2007).

27. A. Miller, J. Long, in Developmental Psychophysiology, L. A. Schmidt, S. J. Segalowitz, Eds.
(Cambridge Univ. Press, New York, 2007)

28. P. J. Lang, M. M. Bradley, B. N. Cuthbert, Psychol. Rev. 97, 377 (1990).

29. G. D.Wilson, J. R. Patterson, Br.J. Soc. Clin. Psychol. 7, 264 (1968).

30. S. Anders, M. Lotze, M. Erb, W. Grodd, Hum. Brain Mapp. 23, 200 (2004).

3I. C. L. Larson et al., Biol. Psychiatry 60, 410 (2006).

32. D. A. Fitzgerald, M. Angstad, L. M. Jelsone, P. J. Nathan, K. L. Phan, Neuroimage 30, I44 I (2006).

33. N. G. Martin et al., Proc. Natl. Acad. Sci. U.S.A. 83, 4364 (I986)

34. L. Eaves et al., Twin Res. 2, 62 (I999).

35. J. R. Alford, C. L. Funk, J. R. Hibbing, Am. Polit. Sci. Rev. 99, 153 (2005).

36. J. H. Fowler, L. A. Baker, C. T. Dawes, Am. Polit. Sci. Rev. 102, 233 (2008).

37. Z. F. Mainen, Nat. Neurosci. I0, I5I I (2007).

38. H. Bracha, D. Yoshioka, N. Masakawa, D. Stockman, J. Affect. Disord. 88, I 9 (2005).

39. C. A. Ponder et al., T. C. Gilliam, A.A. Palmer, Genes Brain Behav. 6, 736 (2007).

40. A. R. Hariri et al., Science 297, 400 (2002).

4I. We thank E. Whitaker, C. Jacobs, B. Sexton, K.A. Espy, J. Brehm, D. Bulling, and the James Long Company for their invaluable assistance. Financial support was provided by the NSF (SES-072I 378 and SES-072I707), the ManTech Corporation, and the University of Nebraska-Lincoln's Strategic Research Cluster Grant program. 
Supporting Material (also online at www.sciencemag.org/cgi/content/full/321/5896/1667/DC1)

- Description of sampling procedures

- General methods

- Descriptive statistics

- Supplementary analyses of political attitudes

- Figure S1

- Tables S1-S6

- Survey instrument

\section{Materials and Methods}

\section{Sample Screening}

Subjects were recruited in May of 2007 by the Bureau of Sociological Research at the University of Nebraska-Lincoln (BOSR). BOSR contacted a random sample of residents of Lincoln, Nebraska. This initial telephone call followed an introductory letter and was used to pose a limited number of items to respondents with the intention of obtaining a group of individuals with strong political convictions toward whom intense and more focused investigation would be directed. The following three questions were used to screen potential subjects. Yes or no response categories were given for all three questions.

1. Do you follow politics or political issues closely?

2. Is there a certain political issue or set of political issues you feel strongly about?

3. Have you ever supported a particular political issue or cause?

A total of 1310 people were contacted and 608 of them completed the screening items. Subjects were recruited for this particular project only if they responded "yes" to all three questions. A total of 143 respondents did so and were agreeable in principle to coming to the lab. BOSR was able to schedule (and secure the attendance of) 48 individuals at both sessions (survey and physiological) of this project. Health problems rendered the data from one individual unusable and mechanical problems with a sensor spoiled the data from another, leaving a final total of 46 participants. Each was paid $\$ 100$ for their involvement.

\section{General Methods}

Skin conductance level (SCL) was collected from participants using a pair of $\mathrm{Ag} / \mathrm{AgCl}$ electrodes. An isotonic contact medium was applied to a $1 \mathrm{~cm}$ diameter area using a circular adhesive collar on the index finger and middle finger of the left hand in order to facilitate contact. The skin conductance was transduced using a $0.5 \mathrm{Vrms}, 30 \mathrm{~Hz}$ sinusoidal excitation signal via an Isolated Bioelectric Amplifier provided (as was all the equipment herein referenced) by the James Long Company (JLC), Caroga Lake, NY. The signal was digitized at $1 \mathrm{kHz}$, and stored on disk. Finally, each trial was sampled, and a mean of the samples was calculated for each trial.

The orbicularis oculi blink reflex electromyogram (EMG) response was collected from participants using the following procedure. The skin at the lower orbital portion of the orbicularis oculi muscle (underneath the eye) was first abraded at the points of contact using skin abrasive gel. The abrasive gel was removed using isopropyl alcohol and a cotton swab. A contact medium was applied to the $6 \mathrm{~mm} \mathrm{Sn}$ cup electrodes to facilitate contact. The two electrodes were spaced approximately $2-3 \mathrm{~cm}$ apart on the lower orbital portion of the orbicularis oculi, and attached using adhesive collars. A ground electrode was attached on the neck behind the ear using a 
similar procedure. At specified times during the presentation of the visual stimuli, a white noise was generated by the STIM Stimulus Presentation System (JLC) with an upper band limit of 4 $\mathrm{kHz}$ for $50 \mathrm{~ms}$ (zero rise/decay time) at a sound pressure level of $105 \mathrm{~dB}$ to induce a startle response.

The analog EMG data was amplified by a JLC Isolated Bioelectric Amplifier which applied an analog high pass filter at $70 \mathrm{~Hz}$ and an analog low pass filter at $250 \mathrm{~Hz}$. It was then digitized at 1 $\mathrm{kHz}$, and transferred to disk. The digital data was bandpass filtered $(80 \mathrm{~Hz}$ to $240 \mathrm{~Hz}$, sinc convolution filter), rectified, and smoothed using a digital low pass filter (8 ms boxcar convolution filter). Finally, the peak amplitude and peak latency of the signal for each epoch were calculated and stored on disk.

All socio-demographic and attitude data were collected using a self-reported computerbased survey administered with MediaLab software (all demographic, political, and psychological batteries from this survey are reported below). Statistical analysis was carried out using SPSS v.14.0. Multiple regression results reported in main text were taken from a linear ordinary least squares (OLS) regression analysis. This statistical technique assumes linear relationships, and models the relationship between a series of independent variables and a dependent variable as a linear equation. The object is to generate coefficients for the independent variables in this equation that minimize the squared error in the dependent variable. A central advantage of this approach for correlational (as opposed to experimental) research designs is its ability to isolate the impact of a given independent variable by holding the impact of all other independent variables constant. The equations for the multiple regressions reported in the main text take the following form:

Equation 1: Support for Protective Policies $=\dot{a}+\beta 1$ (Mean SCL threatening image $)+\beta 2($ Income $)+\beta 3$ $($ Education $)+\beta 4($ Age $)+\beta 5($ Gender $)+\varepsilon$

Equation 2: Support for Protective Policies $=\dot{a}+\beta 1$ (Mean SCL non-threatening image) $+\beta 2$ (Income) $+\beta 3($ Education $)+\beta 4($ Age $)+\beta 5($ Gender $)+\varepsilon$

Equation 3: Support for Protective Policies $=\dot{a}+\beta 1$ (Mean blink amplitude) $+\beta 2($ Income $)+\beta 3$ $($ Education $)+\beta 4($ Age $)+\beta 5($ Gender $)+\varepsilon$

Where $a$ represents a constant, $\beta$ represents the independent variable coefficient estimated and reported in the main text, and $\varepsilon$ represents an error term. While linear regression models are a standard technique in the social sciences where correlational designs are common, the validity of estimates generated by OLS multiple regression are critically dependent upon a series of assumptions, notably that the residuals contained in the error term are normally distributed, have a mean of zero and constant variance. Examination of residuals from the regression models just described suggests that these assumptions are satisfied. The mean residual for all three regressions described above was .000, and examination of normal probability plots shows a reasonable approximation of a normal distribution. We also examined standardized residuals to look for potentially influential outliers. Standardized residuals ranged from -1.8 to 2.1 in Equation 1, -1.66 to 1.57 in equation 2, and from -1.59 to 1.96 in equation 3 . These ranges are all within the bounds of what we would expect a normal distribution of residuals, with no extreme outliers in the tails that could potentially bias our results. Error variance was checked using visual inspection of scatter plots of standardized predicted values on standardized residuals. No discernible violations of the constant error variance assumption were detected.

We also tested for multicollinearity among the independent variables. Technically, as long as no independent variable is a perfect linear combination of other independent variables in the model no fundamental assumption of OLS regression is violated. High levels of multicollinearity, 
however, can create inefficient if not biased estimators and raise questions about the validity of significance tests. No serious levels of multicollinearity were detected-Variance Inflation Factors (VIFs) for all independent variables in all three equations were between 1.0 and 1.1, well below the 5.0 that serves as a standard guideline for indicating problematic levels of multicollinearity. All our diagnostic tests, in short, indicated the multiple regression coefficients reported in the text are efficient and unbiased estimators. All significance tests reported on these coefficients are twotailed t-tests.

\section{Descriptive Statistics: Independent Variables}

Our sample was $\mathrm{N}=46$. Variable measurement and descriptive statistics on the independent variables for our sample are as follows:

SCL Change, Threatening images: Mean logged SCL during exposure to threatening stimuli (data collected as described above) subtracted from mean logged SCL during preceding interstimulus interval (no stimuli on screen). Data were logged to normalize distributions.
Mean:
.004
Standard Deviation: $\quad .022$
Range:
.10

SCL Change, Non-Threatening Images: Mean logged SCL during exposure to nonthreatening stimuli (as described above) subtracted from mean logged SCL during preceding inter-stimulus interval (no stimuli on screen). Data were logged to normalize distributions.

$\begin{array}{ll}\text { Mean: } & -.0025 \\ \text { Standard Deviation: } & .021 \\ \text { Range: } & .16\end{array}$

Mean Amplitude: Mean logged blink amplitude (data collected as described above).

$\begin{array}{lr}\text { Mean: } & .47 \\ \text { Standard Deviation: } & .93 \\ \text { Range: } & 4.14\end{array}$

Age: Measured as year born.

Mean:

Standard Deviation: $\quad 7.84$

Range:

\section{5}

36

Gender: A nominal variable with 1 indicating female, 0 indicating male (data collected from selfreport survey)
N (Pct) Male:
N (Pct) Female:

Income: Current family income measured on a 6-point scale (data collected from selfreport survey).

Under $\$ 20,000$

$\$ 20,000$ to $\$ 40,000 \mathrm{~N}$ (Pct):

$\$ 40,001$ to $\$ 60,000 \mathrm{~N}$ (Pct):

$\$ 60,001$ to $\$ 80,000 \mathrm{~N}$ (Pct):

$\$ 80,001$ to $\$ 100,000 \mathrm{~N}$ (Pct):

More than $\$ 100,000 \mathrm{~N}$ (Pct):
$0(0)$

$11(22.9)$

$14(29.2)$

7 (14.6)

$5(10.4)$

$9(18.8)$ 
Education: Highest level of education achieved measured on a 6-point scale (data collected from self-report survey).

$\begin{array}{lc}\text { Did Not Finish High School } & 0(0) \\ \text { High school N (Pct): } & 5(12.5) \\ \text { Trade School N (Pct: } & 3(6.3) \\ \text { Some College N (Pct) } & 4((8.3) \\ \text { College Graduate N (Pct) } & 9(18.8) \\ \text { College plus N (Pct) } & 24(50)\end{array}$

These distributions are generally unremarkable except perhaps for the high percentage of participants with at least a college degree-a function no doubt of the population being drawn from a college town as well as of our practice of screening for individuals with substantial interest in politics (a group more likely to be well-educated).

\section{Descriptive Statistics: Dependent Variable}

The dependent variable used in the main text is an additive index of 18 issue items based on a standard Wilson-Patterson battery. For each issue, respondents were asked to "please indicate whether you agree or disagree with the topic listed," and were given "agree," "disagree," and "uncertain" response options. These options were coded as " 1 " when they indicated support for protective policies (e.g. for agreeing with the death penalty, or for disagreeing with pacifism), " 0 " when they indicated opposition to protective policies (e.g. for disagreeing with the Patriot act, or agreeing with pornography), and ".5" for an uncertain response. Table S1 reports percentage of respondents $(\mathrm{N}=46)$ coded as protective policy support (i.e. as a " 1 ") for each issue item. Note that percentages do not always indicate percent agreeing with a particular issue. For example, the 80 percent for illegal immigration indicates that a large majority of our sample took a protective posture on this issue; i.e., they disagreed with illegal immigration and were thus coded as " 1 ".

\section{SOM Text}

It is important for readers to recognize that our results do not suggest that one type of physiological response to threat is more normal or "better" than another and thus do not suggest normative priority for a certain cluster of political attitudes. Rather, the message is simply that people differ in their degree of response to threat and that these differences are likely connected to political attitudes. As such, our findings do not necessarily give ammunition to either the political right or the political left (obvious problems attend both over-reaction and under-reaction to the presence of threats in the environment). Instead, we hope our findings may promote understanding across the political spectrum by helping to explain why contrary political beliefs frequently seem so baffling and even frustrating. Political opponents may simply experience the world differently and this situation may be why intensely political people tend to talk past each other. An identical situation may strike one individual as a grave threat to the social unit whereas to another individual it may seem no big deal. Thus, some may see extreme interrogation techniques as necessary to protect America whereas others believe those same techniques to be wholly inappropriate and immoral.

The particular collection of issue positions we employ as indicative of a desire to protect existing social structures from both external and internal threats is certainly open to challenge. We welcome further refinements in identifying the specific attitudes that are and are not connected to physiological traits. We recognize that claims can be made that the social unit is protected more by, say, banning warrantless searches and permitting pornography than by permitting warrantless searches and banning pornography but we posit that those favoring 
warrantless searches and pornography bans are more likely to couch their argument in terms of protecting of the social unit than are those taking the contrary positions (few arguments for permitting pornography contend that doing so will make society stronger while arguments against pornography often invoke the need to prevent the unraveling of the social fabric).

In addition to the analyses reported in the main text, we conducted a number of secondary analyses to check the robustness of our primary findings. These included testing for gender effects in our key variables. We could detect no such effects in simple difference of means tests. The means by gender on our dependent and physiological variables, along with the results of difference of means tests, are reported in Table S3. None of these differences attained statistical significance at the $p<.05$ level using 2-tailed $t$-tests.

We also ran a series of analyses that used the same multiple regression model specification as reported in the OLS tables in the main text, but with different variants of the dependent variable. These included using individual issue items to create separate indexes for "internal" (an additive index that used death penalty, obedience, school prayer, biblical truth, pre-marital sex, gay marriage, abortion rights and pornography) versus "external" (an additive index that used military spending, Iraq war, illegal immigration, foreign aid, patriot act, pacifism, and warrantless searches) threats. The physiological response variables were highly correlated with political attitudes for each of these two subsets of our overall index of socially protective policies. Interestingly (and consistent with previous findings on the distinct components of ideology (1-3), when we regressed support for an index of four economic positions (lower taxes, welfare spending, small government, free trade) on the physiological variables as well as the four sociodemographic controls, neither skin conductance nor startle blink amplitude was statistically significant. It would seem physiological response to threat is related to policies pertaining to social protection but not to economic policies. This result is consistent with our expectations and indicates that physiological responses to threat are connected to socially protective policy positions but not to economic policy positions.

We also ran multiple regression analyses on each of the individual items used to create the additive index of support for protective policies. In these analyses we used the same model specification employed in the main text. In this series of analyses we did find that the physiological variables had stronger predictive capabilities for some items over others. Both SCL for threatening images and mean blink amplitude were statistically significant predictors of attitudes on gay marriage, abortion rights, school prayer, gun control and warrantless searches. Neither variable was a statistically significant predictor for pornography, compromise, patriotism, or military spending (this is not surprising since, as noted in Table S1, attitudes toward pornography, compromise, and patriotism are all extremely lopsided and thus leave minimal variance to explain). For all other items, one of the predictors (SCL for threatening images and mean blink amplitude) was significant, but not the other.

We also conducted a secondary analysis that combined the SCL measures by subtracting mean SCL for threatening images from the mean SCL for non-threatening images. Positive numbers for the resulting variable thus indicate an individual who has higher mean SCL readings in response to threatening images compared a baseline mean SCL for non-threatening images. Given the analysis presented in the main text we would expect this variable to be a positive predictor of support for protective policies. A multiple OLS regression that includes this SCL difference variable along with our demographic controls confirms this expectation. The results of this regression analysis are reported in Table S2.

Finally, since politically inclined individuals (remember, only individuals who answered yes to all three screening questions were eligible for participation) tend to favor policy positions that place them somewhere other than the political middle, our sample is not normally distributed on our central dependent variable, support for socially protective policies. A histogram of the distribution of our issue index measuring support for such policies (i.e., the dependent variable 
in our multiple regression analysis) is presented in Figure S1. Though diagnostics of our the multiple regression analyses presented in the main text (reported above) indicate that the assumption of normality of residuals is not violated, we wanted to make sure that the highly bimodal distribution of our dependent variable was not affecting our results. Accordingly, we created a nominal variable that reflects the bimodal nature of the distribution reported in Figure S1 by cutting the dependent variable at the median. This divided our sample into two groups, those with the highest levels of support for protective policies and those with the lowest levels of support for protective policies. We then used this binary index to assess whether the physiological variables were capable of correctly classifying individuals into high or low groups. For this task, we used binary logistic regression (OLS linear regression is an inappropriate technique for use with nominal variables). The results of this analysis are reported in Tables S4S6.

These results are consistent with those reported in the main text. Compared to participants who are below the median in support for socially protective policies, those

participants above the median are more likely to register physiological reactions to noises and threatening images (but not to non-threatening images).

Finally, we conducted three separate regressions similar in all cases to the multiple regression SCL threat model reported in the main text except we disaggregated the SCL threat measure; i.e., we used separate measures for the spider, maggots and bloody man stimuli rather than using a mean of all three images. In all three cases, the coefficient for the disaggregated threat stimuli was in the expected direction, and two of the three were significant at the $\mathrm{p}<.05$ level (2-tailed $t$-test).

To sum up, the secondary analyses are all consistent with the results reported in the main text, suggesting our findings and inferences are robust with regards to measurement and estimation procedures.

\section{References}

1. B.E. Shafer, W.J.M. Claggett, The Two Majorities (The Johns Hopkins Univ. Press, 1995).

2. G.C. Layman, T.M. Carsey, Amer. J. of Pol. Sci. 46, 786 (2002).

3. P. Goren, Polit. Res. Quar. 61, in press (2008).

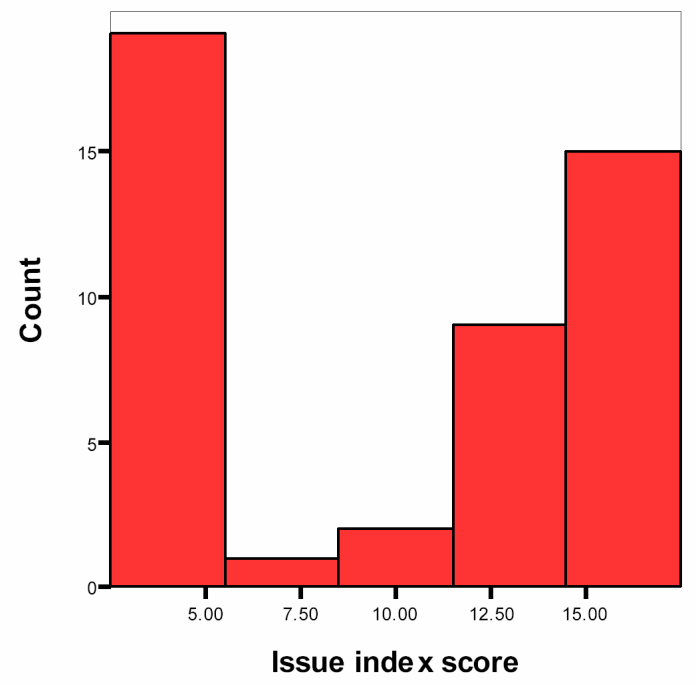

Figure S1. Distribution of Attitudes Towards Protective Policies 
Table S1: Descriptive Statistics for Political Attitudes

\begin{tabular}{lc}
\hline Variable & Percent Supportive (Coded “1") \\
\hline Military Spending & 64.4 \\
Warrantless Searches & 17.8 \\
Death Penalty & 51 \\
Patriot Act & 44.4 \\
Obedience & 62.2 \\
Patriotism & 84.4 \\
Iraq War & 48.9 \\
School Prayer & 48.9 \\
Biblical Truth & 53.3 \\
Pacifism & 53.3 \\
Illegal immigration & 80 \\
Gun Control & 48.9 \\
Foreign Aid & 28.9 \\
Compromise & 17.8 \\
Pre-marital Sex & 44.4 \\
Gay Marriage & 46.7 \\
Abortion Rights & 46.7 \\
Pornography & 4.4
\end{tabular}

Table S2: Support for Protective Policies and Differences in Mean SCL

\begin{tabular}{lcc}
\hline Variable & Coefficient & (Standard Error) \\
\hline SCL Threat - SCL Non-Threat & $46.36^{*}$ & $(21.6)$ \\
Income & -.52 & $(.50)$ \\
Education & $-1.49^{*}$ & $(.495)$ \\
Age & .195 & $(1.05)$ \\
Gender & -2.33 & $(1.44)$ \\
Constant & -363.89 & $(206.65)$ \\
$\mathrm{N}$ & 46 & \\
Adj. R-Square & .29 &
\end{tabular}

Dependent variable: Support for socially protective policies.

$* p<.05$, 2-tailed $t$-test

Table S3: Mean Differences in Key Variables By Gender

\begin{tabular}{lccc}
\hline Variable & Male Mean & Female Mean & $\begin{array}{c}\text { Test of Mean } \\
\text { Differences }\end{array}$ \\
\hline SCL Threat & .0035 & .0045 & $\mathrm{t}=.15, \mathrm{p}=.89$ \\
SCL Non-Threat & -.002 & -.003 & $\mathrm{t}=.14, \mathrm{p}=.88$ \\
Blink Amplitude & .36 & .66 & $\mathrm{t}=1.04, \mathrm{p}=.34$ \\
Support for Protective & 10.03 & 9.4 & $\mathrm{t}=1.72, \mathrm{p}=.09$ \\
Policies & & & \\
\hline
\end{tabular}

Difference of means tests are independent sample t-tests, 2-tailed $t$. 
Supporting Materials, Oxley et al. in Science 321 (2008) Political Attitudes Vary with Physiological Traits

Table S4: SCL For Threatening Images and High/Low Support for Protective Policies

\begin{tabular}{lcc}
\hline Variable & Coefficient & (Standard Error) \\
\hline SCL & $37.24^{*}$ & $(16.6)$ \\
Income & -1.06 & $(1.34)$ \\
Education & $-3.01^{*}$ & $(1.42)$ \\
Age & -4.83 & $(3.33)$ \\
Gender & -1.34 & $(.82)$ \\
Constant & $6.54^{*}$ & $(2.86)$ \\
N & 46 & \\
Nagelkerke R-Square & .41 &
\end{tabular}

Dependent variable: 1,0 variable where $1=$ high support for protective policies.

${ }^{*} \mathrm{p}<.05$, 2-tailed t-test

Table S5: SCL For Non-Threatening Images and High/Low Support for Protective Policies

\begin{tabular}{lcc}
\hline Variable & Coefficient & (Standard Error) \\
\hline SCL & -2.86 & $(15.73)$ \\
Income & -1.03 & $(1.23)$ \\
Education & $-2.59^{*}$ & $(1.32)$ \\
Age & -3.72 & $(3.00)$ \\
Gender & -1.15 & $(.72)$ \\
Constant & $5.5^{*}$ & $(2.25)$ \\
N & 46 & \\
Nagelkerke R-square & .29 & \\
\hline
\end{tabular}

Dependent variable: 1,0 variable where 1 =high support for protective policies.

${ }^{*} \mathrm{p}<.05$, 2-tailed t-test

Table S6: Blink Amplitude and High/Low Support for Protective Policies

\begin{tabular}{lcc}
\hline Variable & Coefficient & (Standard Error) \\
\hline Mean Amplitude & $1.31^{*}$ & $(.53)$ \\
Income & -1.17 & $(1.41)$ \\
Education & $-4.01^{*}$ & $(1.57)$ \\
Age & -5.05 & $(3.83)$ \\
Gender & $-1.82^{*}$ & $(.88)$ \\
Constant & $7.23^{*}$ & $(2.96)$ \\
N & 46 & \\
Adj. R-Square & .47 &
\end{tabular}

Dependent variable: 1,0 variable where 1=high support for protective policies.

${ }^{*} \mathrm{p}<.05$, 2-tailed t-test 


\section{Appendix 1: Survey Instrument}

All subjects took an extensive computer-based survey questionnaire that included demographic questions, questions on political and issue preferences, and a series of psychological and personality batteries. These questions and their associated coding scales are reproduced below.

\section{Demographic questions}

demog1 What is the highest level of education you have completed?

Scale: 1-Did not finish high school, 2-High school graduate, 3-Trade school, 4-Some college, 5-College degree, 6-College degree +

demog2 What is your occupation?

Scale: 1-Clerical, 2-Professional, 3-Business, self-employed, 4-Business/corporation, 5- Other white collar, 6Service industry, 7-Custodial/factory worker, 8-Construction, 9- Other blue collar, 10-Homemaker, 11Student, 12-Unemployed

demog3 What is your family income?

Scale: 1-Under $\$ 20,000$, 2-\$20,000-\$40,000, 3-\$40,001-\$60,000, 4-\$60,001-\$80,000, 5- \$80,001-\$100,000, 6-Over $\$ 100,000$

demog4 In what year were you born? Please just enter the last two digits of the year in which you were born (i.e. if you were born in 1982, enter 82).

Scale: Fill-in-the-blank answer

demog5 Which of the following best describes your race?

Scale: 1-African-American, 2-Hispanic, 3-Asian-American, 4-Native-American, 5- White, 6-Other

demog6 What is your gender?

Scale: 1-Male, 2-Female

demog7 How often do you attend religious services?

Scale: 1-Never, 2-Occasionally, 3-Once or twice a month, 4-Once or more per week

demog8 What is your current marital status?

Scale: 1-Single, 2-Married, 3-Divorced, 4-Widowed, 5-Remarried, 6-Living together, never married

demog9 Do you have children?

Scale: 1-Yes, 2-No

demog10 As an adult, have you ever been involved in a physical confrontation with another person?

Scale: 1-Yes, 2-No

demog11 Have you ever been arrested for something other than a minor misdemeanor such as a speeding ticket?

Scale: 1-Yes, 2-No

demog12 On average, how many alcoholic beverages do you drink a week?

Scale: 1-0, 2-1-5, 3-6-10, 4-11-15, 5-16-20, 6-More than 20 
Supporting Materials, Oxley et al. in Science 321 (2008) Political Attitudes Vary with Physiological Traits

\section{Wilson-Patterson Issue Battery}

wp1 Please indicate whether you agree or disagree with the topic listed below: School prayer Scale: 1-Agree, 2-Disagree, 3-Uncertain

wp2 Please indicate whether you agree or disagree with the topic listed below: Pacifism Scale: 1-Agree, 2-Disagree, 3-Uncertain

wp3 Please indicate whether you agree or disagree with the topic listed below: Socialism Scale: 1-Agree, 2-Disagree, 3-Uncertain

wp4 Please indicate whether you agree or disagree with the topic listed below: Pornography Scale: 1-Agree, 2-Disagree, 3-Uncertain

wp5 Please indicate whether you agree or disagree with the topic listed below: Illegal Immigration Scale: 1-Agree, 2-Disagree, 3-Uncertain

wp6 Please indicate whether you agree or disagree with the topic listed below: Women's equality Scale: 1-Agree, 2-Disagree, 3-Uncertain

wp7 Please indicate whether you agree or disagree with the topic listed below: Death Penalty Scale: 1-Agree, 2-Disagree, 3-Uncertain

wp8 Please indicate whether you agree or disagree with the topic listed below: Patriot Act Scale: 1-Agree, 2-Disagree, 3-Uncertain

wp9 Please indicate whether you agree or disagree with the topic listed below: Premarital Sex Scale: 1-Agree, 2-Disagree, 3-Uncertain

wp10 Please indicate whether you agree or disagree with the topic listed below: Gay marriage Scale: 1-Agree, 2-Disagree, 3-Uncertain

wp11 Please indicate whether you agree or disagree with the topic listed below: Abortion rights Scale: 1-Agree, 2-Disagree, 3-Uncertain

wp12 Please indicate whether you agree or disagree with the topic listed below: Evolution Scale: 1-Agree, 2-Disagree, 3-Uncertain

wp13 Please indicate whether you agree or disagree with the topic listed below: Patriotism Scale: 1-Agree, 2-Disagree, 3-Uncertain

wp14 Please indicate whether you agree or disagree with the topic listed below: Biblical truth Scale: 1-Agree, 2-Disagree, 3-Uncertain

wp15 Please indicate whether you agree or disagree with the topic listed below: Iraq War Scale: 1-Agree, 2-Disagree, 3-Uncertain

wp16 Please indicate whether you agree or disagree with the topic listed below: Welfare spending Scale: 1-Agree, 2-Disagree, 3-Uncertain

wp17 Please indicate whether you agree or disagree with the topic listed below: Tax Cuts Scale: 1-Agree, 2-Disagree, 3-Uncertain

wp18 Please indicate whether you agree or disagree with the topic listed below: Gun control Scale: 1-Agree, 2-Disagree, 3-Uncertain 
Supporting Materials, Oxley et al. in Science 321 (2008) Political Attitudes Vary with Physiological Traits

wp19 Please indicate whether you agree or disagree with the topic listed below: Military spending Scale: 1-Agree, 2-Disagree, 3-Uncertain

wp20 Please indicate whether you agree or disagree with the topic listed below: Warrantless searches Scale: 1-Agree, 2-Disagree, 3-Uncertain

wp21 Please indicate whether you agree or disagree with the topic listed below: Globalization Scale: 1-Agree, 2-Disagree, 3-Uncertain

wp22 Please indicate whether you agree or disagree with the topic listed below: Pollution control Scale: 1-Agree, 2-Disagree, 3-Uncertain

wp23 Please indicate whether you agree or disagree with the topic listed below: Small government Scale: 1-Agree, 2-Disagree, 3-Uncertain

wp24 Please indicate whether you agree or disagree with the topic listed below: School standards Scale: 1-Agree, 2-Disagree, 3-Uncertain

wp25 Please indicate whether you agree or disagree with the topic listed below: Foreign aid Scale: 1-Agree, 2-Disagree, 3-Uncertain

wp26 Please indicate whether you agree or disagree with the topic listed below: Free trade Scale: 1-Agree, 2-Disagree, 3-Uncertain

wp27 Please indicate whether you agree or disagree with the topic listed below: Obedience Scale: 1-Agree, 2-Disagree, 3-Uncertain

wp28 Please indicate whether you agree or disagree with the topic listed below: Compromise Scale: 1-Agree, 2-Disagree, 3-Uncertain

\section{Political Questions}

pol1 Are you registered to vote?

Scale: 1-Yes, 2-No

pol2 Do you usually vote in elections?

Scale: 1-Yes, 2-No

pol3 How often do you discuss political issues with other people?

Scale: 5 choices: 1-Very often, 2-Often, 3-Sometimes, 4-Once in a while, 5-Rarely

pol4 To what extent are you comfortable discussing politics with individuals who disagree with you? Scale: 5 choices: 1-Very uncomfortable, 2-Moderately uncomfortable, 3-Neither uncomfortable nor comfortable, 4-Moderately comfortable, 5-Very comfortable

pol5 How do you feel when someone disagrees with you on a political issue? Scale: 4 choices: 1-Extremely angry, 2-Mildly angry, 3-Annoyed, 4-Doesn't bother me at all

pol6 On a scale of 1-7, with one being strongly liberal, 4 being centrist, and 7 being strongly conservative, where would you place yourself?

Scale: 7 point scale, from strongly liberal to centrist to strongly conservative

pol7 Do you consider yourself a Democrat, a Republican, an Independent, or other?

Scale: 8 point scale, 1-Strong Democrat, 2-Weak Democrat, 3-Independent, leaning Democrat, 4Independent, 5-Independent, leaning Republican, 6-Weak Republican, 7- Strong Republican, 8-Other 
pol8 Do you think there is a need for a third party in the United States today?

Scale: 1-Yes, 2-No

pol9 Is there any meaningful difference between the Democratic and Republican parties?

Scale: 1-Yes, 2-No

pol10 Is there any political issue you feel strongly about?

Scale: 1-Yes, 2-No

pol11 Which political issue do you feel most strongly about? Please try to give a one or two word answer (for example, "illegal immigration", "abortion", "tax reform"). If you feel strongly about several, just list one for now.

Scale: Fill-in-the-blank answer

pol13 How strongly do you feel about this issue? Imagine a scale of strong feelings ranging from 1-10 with 1 representing an issue which you do not care about al all and 10 representing an issue about which you care intensely.

Scale: 10 point scale, with 1-Do not care about issue at all and 10-Care about issue intensely

pol14 We are interested in whether or not you have ever taken any kind of action in the political arena to promote this issue. Have you: Voted for particular candidates because of their position on this issue

Scale: 1-Yes, 2-No

pol15 We are interested in whether or not you have ever taken any kind of action in the political arena to promote this issue. Have you: Campaigned for particular candidates because of their position on this issue

Scale: 1-Yes, 2-No

pol16 We are interested in whether or not you have ever taken any kind of action in the political arena to promote this issue. Have you: Contributed money to particular candidates because of their position on this issue

Scale: 1-Yes, 2-No

pol17 We are interested in whether or not you have ever taken any kind of action in the political arena to promote this issue. Have you: Contacted elected officials to encourage them to support your issue position

Scale: 1-Yes, 2-No

pol18 We are interested in whether or not you have ever taken any kind of action in the political arena to promote this issue. Have you: Tried to persuade other citizens to support your position on this issue Scale: 1-Yes, 2-No

pol19 We are interested in whether or not you have ever taken any kind of action in the political arena to promote this issue. Have you: Belonged to an organization that promotes your position on this issue Scale: 1-Yes, 2-No

pol20 We are interested in whether or not you have ever taken any kind of action in the political arena to promote this issue. Have you: Attended meetings that promote your position on this issue Scale: $1-Y e s, 2-\mathrm{No}$

pol21 We are interested in whether or not you have ever taken any kind of action in the political arena to promote this issue. Have you: Signed a petition to promote your position on this issue

Scale: 1-Yes, 2-No 
pol22 We are interested in whether or not you have ever taken any kind of action in the political arena to promote this issue. Have you: Ever taken part in a protest or demonstration on behalf of this issue

Scale: $1-Y e s, 2-\mathrm{No}$

pol23 We are interested in whether or not you have ever taken any kind of action in the political arena to promote this issue. Have you: Threatened or participated in a boycott

Scale: $1-Y e s, 2-\mathrm{No}$

pol24 We are interested in whether or not you have ever taken any kind of action in the political arena to promote this issue. Have you: Threatened disruptive activity

Scale: 1-Yes, 2-No

pol25 We are interested in whether or not you have ever taken any kind of action in the political arena to promote this issue. Have you: Threatened or supported violent activity

Scale: 1-Yes, 2-No

pol26 Do you think government decision makers are responsive to your views on this issue? Please answer using a 1-5 scale, where 5 indicates that government is highly responsive and 1 indicates government is not responsive at all.

Scale: 5 point scale, 1-Government not responsive at all, 5-Government highly responsive

pol27 How responsive do you think government decision makers are to people who STRONGLY DISAGREE with your views on this issue? Please answer using a 1-5 scale, where 5 indicates government is highly responsive and 1 indicates government is not responsive at all

Scale: 5 point scale, 1-Government not responsive at all, 5-Government highly responsive

pol28 Do you see the political influence of you and those who share your views on this issue as increasing, decreasing, or staying about the same?

Scale: 1-Increasing, 2-Decreasing, 3-Staying about the same

pol29 Do you see the political influence of those who do NOT share your views on this issue as increasing, decreasing, or staying about the same?

Scale: 1-Increasing, 2-Decreasing, 3-Staying about the same

pol30 On a scale of 1-7, with 1 being "making no difference" and 7 being "making a great deal of difference", how much do you think the following activity is likely to matter in the extent to which government pays attention to an issue: Voting

Scale: 7 point scale, 1-Makes no difference to 7-Makes a great deal of difference

pol31 On a scale of 1-7, with 1 being "making no difference" and 7 being "making a great deal of difference", how much do you think the following activity is likely to matter in the extent to which government pays attention to an issue: Contacting a public offi Scale: 7 point scale, 1-Makes no difference to 7-Makes a great deal of difference

pol32 On a scale of 1-7, with 1 being "making no difference" and 7 being "making a great deal of difference", how much do you think the following activity is likely to matter in the extent to which government pays attention to an issue: Signing a petition

Scale: 7 point scale, 1-Makes no difference to 7-Makes a great deal of difference

pol33 On a scale of 1-7, with 1 being "making no difference" and 7 being "making a great deal of difference", how much do you think the following activity is likely to matter in the extent to which government pays attention to an issue: Joining a group that pro

Scale: 7 point scale, 1-Makes no difference to 7-Makes a great deal of difference 
pol34 On a scale of 1-7, with 1 being "making no difference" and 7 being "making a great deal of difference", how much do you think the following activity is likely to matter in the extent to which government pays attention to an issue: Discussing the issue wit

Scale: 7 point scale, 1-Makes no difference to 7-Makes a great deal of difference

pol35 On a scale of 1-7, with 1 being "making no difference" and 7 being "making a great deal of difference", how much do you think the following activity is likely to matter in the extent to which government pays attention to an issue: Mass demonstration

Scale: 7 point scale, 1-Makes no difference to 7-Makes a great deal of difference

pol36 On a scale of 1-7, with 1 being "making no difference" and 7 being "making a great deal of difference", how much do you think the following activity is likely to matter in the extent to which government pays attention to an issue: Violence

Scale: 7 point scale, 1-Makes no difference to 7-Makes a great deal of difference

pol37 If you had to choose, which do you think is more important--supporting candidates who openly share your views, or opposing candidates who openly disagree with your views?

Scale: 1-Supporting candidates who openly share your views, 2-Opposing candidates who openly disagree with your views

pol38 Which of the following best describes your perspective on those who STRONGLY DISAGREE with you on this issue?

Scale: 1-They just have a different point of view and we agree to disagree, 2-They have a point of view that could make society worse, 3 -They have a point of view that is dangerous

pol39 How do you think you and those who share your views on this issue are treated by government and the political world in general?

Scale: 1-Our perspective is given a fair shake, 2-Our perspective has to work hard to get its due, 3-Our perspective is unfairly ignored and attacked

pol40 We asked you several questions regarding the issue about which you feel the most strongly but we are interested in whether you feel strongly about any political issues besides the one you have been thinking of. Do you have at least one other political is Scale: 1-Yes, 2-No

pol41 How strongly do you feel about this issue? Use the same scale of strong feelings you used to judge the first issue, a number ranging from 1-10, with 1 representing an issue which you do not care about al all and 10 representing an issue about which you care

Scale: 10 point scale, with 1-Do not care about issue at all to 10-Care about issue intensely

pol42 More generally, would you say that you care intensely about a large number of political issues or that you tend to focus your intensity on one or at least a limited number of issues?

Scale: 1-I care intensely about a large number of issues, 2-I tend to focus my intensity on a limited number of issues, 3-I care intensely about only one issue

pol43 Most everyone abhors violence, but do you think there are any circumstances where violence is likely to be productive in furthering a political position or cause?

Scale: 7 point scale, 1-Violence is counterproductive to 4-Violence can be counterproductive or productive to 7 -Violence is productive

pol44 Can violence be morally justified in order to get needed progress on an important issue? Scale: 5 point scale, 1-Violence is definitely not justified to 3-Violence may or may not be justified to 5Violence is definitely justified

pol45 If you knew someone who had committed an act of violence in the name of a political cause about which they felt very strongly, would you...

Scale: 1-Praise the individual for the act, 2-Criticize the individual for the act, 3-Neither praise nor criticize 


\section{Empathy battery}

emp1 Please indicate whether you strongly disagree, disagree, agree or strongly agree with the following statement: I find it hard to know what to do in a social situation. Scale: 1-Strongly Disagree, 2-Disagree, 3-Agree, 4-Strongly Agree

emp2 Please indicate whether you strongly disagree, disagree, agree or strongly agree with the following statement: People often tell me that I went too far in driving my point home in discussion.

Scale: 1-Strongly Disagree, 2-Disagree, 3-Agree, 4-Strongly Agree

emp3 Please indicate whether you strongly disagree, disagree, agree or strongly agree with the following statement: It doesn't bother me too much if I am late meeting a friend.

Scale: 1-Strongly Disagree, 2-Disagree, 3-Agree, 4-Strongly Agree

emp4 Please indicate whether you strongly disagree, disagree, agree or strongly agree with the following statement: I can pick up quickly if someone says one thing but means another.

Scale: 1-Strongly Disagree, 2-Disagree, 3-Agree, 4-Strongly Agree

emp5 Please indicate whether you strongly disagree, disagree, agree or strongly agree with the following statement: I am good at predicting how someone will feel.

Scale: 1-Strongly Disagree, 2-Disagree, 3-Agree, 4-Strongly Agree

emp6 Please indicate whether you strongly disagree, disagree, agree or strongly agree with the following statement: If anyone asked me if I liked their haircut, I would reply truthfully, even if I didn't like it. Scale: 1-Strongly Disagree, 2-Disagree, 3-Agree, 4-Strongly Agree

emp7 Please indicate whether you strongly disagree, disagree, agree or strongly agree with the following statement: I can easily tell if someone else is interested or bored with what I am saying.

Scale: 1-Strongly Disagree, 2-Disagree, 3-Agree, 4-Strongly Agree

emp8 Please indicate whether you strongly disagree, disagree, agree or strongly agree with the following statement: I can sense if I am intruding, even if the other person doesn't tell me.

Scale: 1-Strongly Disagree, 2-Disagree, 3-Agree, 4-Strongly Agree

emp9 Please indicate whether you strongly disagree, disagree, agree or strongly agree with the following statement: I usually stay emotionally detached when watching a film. Scale: 1-Strongly Disagree, 2Disagree, 3-Agree, 4-Strongly Agree

emp10 Please indicate whether you strongly disagree, disagree, agree or strongly agree with the following statement: I can usually appreciate the other person's viewpoint, even if I don't agree with it.

Scale: 1-Strongly Disagree, 2-Disagree, 3-Agree, 4-Strongly Agree

\section{Systemizing Battery}

sys1 Please indicate whether you strongly disagree, disagree, agree or strongly agree with the following statement: I prefer to read non-fiction than fiction.

Scale: 1-Strongly Disagree, 2-Disagree, 3-Agree, 4-Strongly Agree

sys2 Please indicate whether you strongly disagree, disagree, agree or strongly agree with the following statement: I do not enjoy games that involve a high degree of strategy.

Scale: 1-Strongly Disagree, 2-Disagree, 3-Agree, 4-Strongly Agree

sys3 Please indicate whether you strongly disagree, disagree, agree or strongly agree with the following statement: I am fascinated by how machines work.

Scale: 1-Strongly Disagree, 2-Disagree, 3-Agree, 4-Strongly Agree 
sys4 Please indicate whether you strongly disagree, disagree, agree or strongly agree with the following statement: When I cook, I do not think about exactly how different methods and ingredients contribute to the final product.

Scale: 1-Strongly Disagree, 2-Disagree, 3-Agree, 4-Strongly Agree

sys5 Please indicate whether you strongly disagree, disagree, agree or strongly agree with the following statement: If I had a collection (e.g., CDs, coins, stamps), it would be highly organized.

Scale: 1-Strongly Disagree, 2-Disagree, 3-Agree, 4-Strongly Agree

sys6 Please indicate whether you strongly disagree, disagree, agree or strongly agree with the following statement: When I learn about historical events, I do not focus on exact dates.

Scale: 1-Strongly Disagree, 2-Disagree, 3-Agree, 4-Strongly Agree

sys7 Please indicate whether you strongly disagree, disagree, agree or strongly agree with the following statement: When I read the newspaper, I am drawn to tables of information, such as football scores or stock market indices.

Scale: 1-Strongly Disagree, 2-Disagree, 3-Agree, 4-Strongly Agree

sys8 Please indicate whether you strongly disagree, disagree, agree or strongly agree with the following statement: I do not tend to watch science documentaries on television or read articles about science and nature.

Scale: 1-Strongly Disagree, 2-Disagree, 3-Agree, 4-Strongly Agree

sys9 Please indicate whether you strongly disagree, disagree, agree or strongly agree with the following statement: I am not very meticulous when I carry out do-it-yourself projects.

Scale: 1-Strongly Disagree, 2-Disagree, 3-Agree, 4-Strongly Agree

sys10 Please indicate whether you strongly disagree, disagree, agree or strongly agree with the following statement: When I read something, I always notice whether it is grammatically correct.

Scale: 1-Strongly Disagree, 2-Disagree, 3-Agree, 4-Strongly Agree

\section{Right Wing Authoritarianism Battery}

rwa1 Please indicate your level of agreement: It is always better to trust the judgment of the proper authorities in government and religion than to listen to the noisy rabble-rousers in our society who are trying to create doubt in people's minds.

Scale: 1-Strongly Disagree, 2-Disagree, 3-Agree, 4-Strongly Agree

rwa2 Please indicate your level of agreement: The only way our country can get through the crisis ahead is to get back to our traditional values, put some tough leaders in power, and silence the troublemakers spreading bad ideas.

Scale: 1-Strongly Disagree, 2-Disagree, 3-Agree, 4-Strongly Agree

rwa3 Please indicate your level of agreement: Our country needs free thinkers who have the courage to defy traditional ways, even if this upsets many people.

Scale: 1-Strongly Disagree, 2-Disagree, 3-Agree, 4-Strongly Agree

rwa4 Please indicate your level of agreement: Our country will be destroyed someday if we do not smash the perversions eating away at or moral fiber and traditional beliefs.

Scale: 1-Strongly Disagree, 2-Disagree, 3-Agree, 4-Strongly Agree

rwa5 Please indicate your level of agreement: Everyone should have their own lifestyle, religious beliefs, and sexual preferences, even if it makes them different from everyone else.

Scale: 1-Strongly Disagree, 2-Disagree, 3-Agree, 4-Strongly Agree 
rwa6 Please indicate your level of agreement: You have to admire those who challenged the law and the majority's view by protesting for women's abortion rights, for animal rights, or to abolish school prayer. Scale: 1-Strongly Disagree, 2-Disagree, 3-Agree, 4-Strongly Agree

rwa7 Please indicate your level of agreement: What our country really needs is a strong determined leader who will crush evil, and take us back to our true path.

Scale: 1-Strongly Disagree, 2-Disagree, 3-Agree, 4-Strongly Agree

rwa8 Please indicate your level of agreement: Some of the best people in our country are those who are challenging our government, criticizing religion, and ignoring the "normal way things are supposed to be done."

Scale: 1-Strongly Disagree, 2-Disagree, 3-Agree, 4-Strongly Agree

rwa9 Please indicate your level of agreement: Our country will be great if we honor the ways of our forefathers, do what the authorities tell us to do, and get rid of the "rotten apples" who are ruining everything.

Scale: 1-Strongly Disagree, 2-Disagree, 3-Agree, 4-Strongly Agree

rwa10 Please indicate your level of agreement: There is no "ONE right way" to live life; everybody has to create their own way.

Scale: 1-Strongly Disagree, 2-Disagree, 3-Agree, 4-Strongly Agree

rwa11 Please indicate your level of agreement: This country would work a lot better if certain groups of troublemakers would just shut up and accept their group's traditional place in society.

Scale: 1-Strongly Disagree, 2-Disagree, 3-Agree, 4-Strongly Agree

\section{Social Dominance Orientation Battery}

sdo1 For the following statement, please indicate your level of agreement/disagreement by selecting the appropriate number from 1 to 7 : Winning is more important than how the game is played.

Scale: 1-Strongly disagree to 7-Strongly agree

sdo2 For the following statement, please indicate your level of agreement/disagreement by selecting the appropriate number from 1 to 7 : Getting ahead by any means necessary.

Scale: 1-Strongly disagree to 7-Strongly agree

sdo3 For the following statement, please indicate your level of agreement/disagreement by selecting the appropriate number from 1 to 7: Sometimes war is necessary to put other countries in their place.

Scale: 1-Strongly disagree to 7-Strongly agree

sdo4 For the following statement, please indicate your level of agreement/disagreement by selecting the appropriate number from 1 to 7 : Inferior groups should stay in their place.

Scale: 1-Strongly disagree to 7-Strongly agree

\section{Machiavellian Battery}

mach1 Please answer 1-Yes, 2-No to the following question: Would you be prepared to deceive someone completely if it were to your advantage?

Scale: $1-Y e s, 2-\mathrm{No}$ 
mach2 Please answer 1-Yes, 2-No to the following question: Would you be prepared to do a bad turn to someone in order to get something you particularly wanted for yourself?

Scale: 1-Yes, 2-No

mach3 Please answer 1-Yes, 2-No to the following question: Do you often act in a cunning way in order to get what you want?

Scale: 1-Yes, 2-No

mach4 Please answer 1-Yes, 2-No to the following question: Would you be prepared to "walk all over people" to get what you want?

Scale: 1-Yes, 2-No

mach5 Please answer 1-Yes, 2-No to the following question: Do you enjoy manipulating people?

Scale: 1-Yes, 2-No

mach6 Please answer 1-Yes, 2-No to the following question: Do you tend to most things with an eye to your own advantage?

Scale: 1-Yes, 2-No

mach7 Please answer 1-Yes, 2-No to the following question: Do you agree that the most important thing in life is winning?

Scale: 1-Yes, 2-No

mach8 Please answer 1-Yes, 2-No to the following question: Would you be prepared to be quite ruthless in order to get ahead in your job?

Scale: 1-Yes, 2-No

mach9 Please answer 1-Yes, 2-No to the following question: Would you be prepared to be humble and honest rather than important and dishonest?

Scale: 1-Yes, 2-No

mach10 Please answer 1-Yes, 2-No to the following question: Would you like to be very powerful?

Scale: 1-Yes, 2-No

\section{Personality Battery}

pers1 I see myself as: Extroverted, enthusiastic

Scale: 7 point scale, with 1-Strongly disagree to 7-Strongly agree

pers2 I see myself as: Critical, quarrelsome

Scale: 7 point scale, with 1-Strongly disagree to 7-Strongly agree

pers3 I see myself as: Dependable, self-disciplined

Scale: 7 point scale, with 1-Strongly disagree to 7-Strongly agree

pers4 I see myself as: Anxious, easily upset

Scale: 7 point scale, with 1-Strongly disagree to 7-Strongly agree

pers5 I see myself as: Open to new experiences, complex

Scale: 7 point scale, with 1-Strongly disagree to 7-Strongly agree

pers6 I see myself as: Reserved, quiet

Scale: 7 point scale, with 1-Strongly disagree to 7-Strongly agree 
Supporting Materials, Oxley et al. in Science 321 (2008) Political Attitudes Vary with Physiological Traits

pers7 I see myself as: Sympathetic, warm

Scale: 7 point scale, with 1-Strongly disagree to 7-Strongly agree

pers8 I see myself as: Disorganized, careless

Scale: 7 point scale, with 1-Strongly disagree to 7-Strongly agree

pers9 I see myself as: Calm, emotionally stable

Scale: 7 point scale, with 1-Strongly disagree to 7-Strongly agree

pers10 I see myself as: Conventional, uncreative

Scale: 7 point scale, with 1-Strongly disagree to 7-Strongly agree

\section{Political Orientation Battery}

soc1 Society works best when...

Scale: 1-People realize the world is dangerous, 2-People assume all those in far away places are kindly

soc2 Society works best when...

Scale: 1-Our leaders are obeyed, 2-Our leaders are questioned

soc3 Society works best when...

Scale: 1-People are rewarded according to merit, 2-People are rewarded according to need

soc4 Society works best when...

Scale: 1-We take care of our own people first, 2-We realize that people everywhere deserve our help

soc5 Society works best when...

Scale: 1-Our leaders stick to their beliefs regardless, 2-Our leaders change positions whenever situations change

soc6 Society works best when...

Scale: 1-Our leaders compromise with their opponents in order to get things done, 2-Our leaders adhere to their principles no matter what

soc7 Society works best when...

Scale: 1-People live according to traditional values, 2-People adjust their values to fit changing circumstances

soc8 Society works best when...

Scale: 1-Our leaders call the shots, 2-Our leaders are forced to listen to others

soc9 Society works best when...

Scale: 1-People take primary responsibility for their welfare, 2-People join together to help others

soc10 Society works best when...

Scale: 1-People recognize the unavoidable flaws of human nature, 2-People recognize that humans can be changed in positive ways

soc11 Society works best when...

Scale: 1-People are proud they belong to the best society there is, 2-People realize that no society is better than any other

soc12 Society works best when...

Scale: 1-Every member contributes, 2-More fortunate members sacrifice to help others 
Supporting Materials, Oxley et al. in Science 321 (2008) Political Attitudes Vary with Physiological Traits

soc13 Society works best when...

Scale: 1-Behavioral expectations are based on an external code, 2-Behavioral expectations are allowed to evolve over the decades

soc14 Society works best when...

Scale: 1-Those who break the rules are punished, 2-Those who break the rules are forgiven 